While not designed as a medium for the publication of original work, Discovery has from time to time been first with significant scientific news. It was, for example, among the first to print the disturbing facts about the sulphur shortage. It campaigned-with apparent success-for the appointment of scientific attachés in British embassies and for experiments on the underground gasification of coal. It has campaigned, so far unsuccessfully, for better pay for science teachers. With its vigorous editor and an established readership at home and abroad, Discovery can be expected to improve both its circulation and its beneficial influence.

\section{Research in Industry}

ON November 27 the members of the Advisory Council of Scientific and Industrial Research and the chairmen and directors of some forty research associations of the Department of Scientific and Industrial Research held a conference in London, at which they discussed in private the education of technologists and technicians in Great Britain. At the luncheon given in conjunction with the conference, Sir Ian Heilbron, chairman of the Advisory Council, made public the important news that, subject to Parliamentary approval, the Government has decided to allow the Department of Scientific and Industrial Research to plan its work on a fiveyear basis, thus giving a continuity and flexibility of policy which the Department has long sought. At the same time the Government is restoring in full the financial cuts made two years ago in the Department's post-war programme for the expansion of its work. After expressing his gratitude to the Government for thus generously implementing the Department's aims, Sir Ian went on to deplore the lack of recognition given by industry in general to the work of scientists and engineers. This is particularly reflected, he said, in the fact that few of the boardrooms in industry contain directors who are persons with high technical qualifications. The other speaker at the luncheon, Lord Woolton, who was deputizing for the Lord President of the Council, stressed the importance of technological education as a key factor in industry and hence of Britain's ability to keep its place in overseas markets in the face of rapidly growing foreign competition. He urged that universities, in particular, should not be averse to the giving of academic rewards to students who want to specialize in a technological field to the exclusion of other subjects.

\section{Education in Meteorology}

THE third annual dinner of the Royal Meteorological Society held on November 20 had this year for its theme "Education in Meteorology", and the guest of honour was Dr. K. W. M. Pickthorn, Parliamentary Secretary to the Ministry of Education. The president of the Society, Dr. O. G. Sutton, in proposing the toast "Education in Science", said that he wonders whether we are not in danger of losing touch with reality by our search for ultimate reality, and whether it would not be worth while to turn some of our attention from the remote, unsub. stantial world of atoms and electrons to more friendly and familiar things, to the clouds and the rain and the skies. Meteorology, which has been so neglected in British universities (with certain exceptions), might well, in his opinion, provide the necessary relief from over-specialization. To be a meteorologist one needs to be a very widely read scientist, for there is scarcely any branch of physics which is not involved in meteorology-it even touches on life itself.

Dr. Pickthorn pointed out that there seems to be broad divisions among school-children between born scientists, who would pursue a scientific career irrespective of their schooling, those who would never become scientists, and a very considerable intermediate body who ought to be scientists and could be, given proper training. He believed that, in teaching science, alaboratory work could be supplemented by meteorological observations, and he thought that even the quite unscientific might be given some notion of how scientists think and work if their interest in the weather could be exploited. Sir Charles Morris, vice-chancellor, University of Leeds, contrasted the positions of pure and applied science in the United Kingdom and stressed the difficulty experienced in attracting students of sufficient calibre towards research in applied science. He felt that the Royal Meteorological Society by its very closeness to Nature could do a great deal in correcting this bias. Appreciation was expressed by Dr. John Brown, chief education officer of the London County Council, for the Society's Popular Lecture, arranged each year for the benefit of sixth-form pupils. The application for tickets this year has been so heavy that a repeat lecture will be given in the County Hall Lecture Theatre.

\section{Science Masters' Association : Annual Meeting}

THE annual meeting for 1954 of the Science Masters' Association will be held in Oxford during December 29, 1953-January 1, 1954, under the presidency of Sir Cyril Hinshelwood. The meeting will open with Sir Cyril's address, given at 8 p.m. on December 29, his theme being "Thoughts on the Evolution of a Scientific Problem". On the following day, J. P. Stephenson and R. Thurlow will demonstrate experiments, afterwards on exhibition in the Clarendon Laboratory, at a lecture entitled "Experiments in Elementary Physics", which will be of special interest to those teaching in secondary modern schools. On December 31 the annual business meeting of the Association will be held ; in the late afternoon the Association's report on "The Teaching of Science in Secondary Modern Schools" will be introduced by some of the members of the committee responsible for the report and will afterwards be critically reviewed by a headmaster of a secondary modern school. Each morning at 10 a.m. there will be three simultaneous lectures on biology, chemistry and physics, respectively; in addition, it will be possible to visit laboratories in the University and discuss problems with the University staff. The afternoon visits will be made to places of interest in Oxford and farther afield. Three exhibitions will be held concurrently with the meeting: in the Dyson Perrins Laboratory the usual exhibitions of apparatus and books by manufacturers and publishers; in the Inorganic Chemistry Laboratory the usual members' exhibition of apparatus and teaching aids; and, also in the Inorganic Chemistry Laboratory, a special exhibition by the Scientific Department of the National Coal Board showing the biological, chemical and physical apparatus and research experiments (with demonstrations) used in the routine and the research laboratories of the Department. Accommodation is available during the meeting at Keble College. Further information can be obtained from the annual meeting secretary of the Association, W. G. Rhodes, Park View, 318 Granville Road, Sheffield 2. 